\title{
Investigating self-recognition in bonobos: Mirror exposure reduces looking time to self but not unfamiliar conspecifics
}

\author{
Gladez Shorland $^{1}$, Emilie Genty ${ }^{1,2}$, Jean-Pascal Guéry ${ }^{3}$, Klaus Zuberbühler $^{\text {Corresp. } 1,4}$ \\ ${ }^{1}$ Department of Comparative Cognition, Institute of Biology, University of Neuchâtel, Neuchâtel, Switzerland \\ 2 Institute of Work and Organizational Psychology, University of Neuchâtel, Neuchâtel, Switzerland \\ 3 La Vallée des Singes Zoological park, Romagne, France \\ ${ }^{4}$ School of Psychology and Neuroscience, University of St. Andrews, St Andrews, Scotland (United Kingdom) \\ Corresponding Author: Klaus Zuberbühler \\ Email address: klaus.zuberbuehler@unine.ch
}

The question of whether animals have some sort of self-awareness is a topic of continued debate. A necessary precondition for self-awareness is the ability to visually discriminate the self from others, which has traditionally been investigated through mirror selfrecognition experiments. Although great apes generally pass such experiments, interpretations of results have remained controversial. The aim of this study was to investigate how bonobos (Pan paniscus) respond to different types of images of themselves and others, both before and after prolonged mirror exposure. We first presented presumably mirror-naive subjects with representations of themselves in three different ways (mirror image, contingent and non-contingent video footage) as well as representations of others (video footage of known and unknown conspecifics). We found that subjects paid significantly less attention to contingent images of themselves (mirror image, video footage) than to non-contingent images of themselves and unfamiliar individuals, suggesting they perceived the non-contingent self-image as novel. We then provided subjects with three months of access to a large mirror centrally positioned in the enclosure. Following this manipulation, subjects showed significantly reduced interest in the non-contingent self-images, while interest in unknown individuals remained unchanged, suggesting that the mirror experience has led to a fuller understanding of their own self. We discuss implications of this preliminary investigation for the on-going debate on self-awareness in animals. 
1 Investigating self-recognition in bonobos: Mirror exposure reduces looking time to self but

2 not unfamiliar conspecifics

3

4 Gladez Shorland ${ }^{1}$, Emilie Genty ${ }^{1,2}$, Jean-Pascal Guéry ${ }^{3}$, Klaus Zuberbühler ${ }^{1,4}$

$5{ }^{1}$ Department of Comparative Cognition, Institute of Biology, University of Neuchâtel,

6 Neuchâtel, Switzerland; ${ }^{2}$ Institute of Work and Organizational Psychology, University of

7 Neuchâtel, Neuchâtel, Switzerland; ${ }^{3}$ La Vallée des Singes Zoological park, Romagne, France; 4

8 School of Psychology and Neurosciences, University of St Andrews, St Andrews, Scotland, UK.

9

10 Corresponding author: Klaus Zuberbühler (klaus.zuberbuehler@unine.ch) 


\section{Abstract}

12 The question of whether animals have some sort of self-awareness is a topic of continued debate.

13 A necessary precondition for self-awareness is the ability to visually discriminate the self from

14 others, which has traditionally been investigated through mirror self-recognition experiments.

15 Although great apes generally pass such experiments, interpretations of results have remained

16 controversial. The aim of this study was to investigate how bonobos (Pan paniscus) respond to

17 different types of images of themselves and others, both before and after prolonged mirror

18 exposure. We first presented presumably mirror-naive subjects with representations of

19 themselves in three different ways (mirror image, contingent and non-contingent video footage)

20 as well as representations of others (video footage of known and unknown conspecifics). We

21 found that subjects paid significantly less attention to contingent images of themselves (mirror

22 image, video footage) than to non-contingent images of themselves and unfamiliar individuals,

23 suggesting they perceived the non-contingent self-image as novel. We then provided subjects

24 with three months of access to a large mirror centrally positioned in the enclosure. Following this

25 manipulation, subjects showed significantly reduced interest in the non-contingent self-images,

26 while interest in unknown individuals remained unchanged, suggesting that the mirror

27 experience has led to a fuller understanding of their own self. We discuss implications of this

28 preliminary investigation for the on-going debate on self-awareness in animals. 


\section{Introduction}

31 A fundamental question in comparative cognition is whether, or to what degree, non-human animals have something akin to self-awareness, that is, whether they can recognise themselves as separate from others and the environment. Related to this is the question of whether animals,

34 other than humans, have some understanding of their own mental states. It is generally accepted that self-awareness presupposes self-recognition of the body, such as its visual appearance, which is empirically easier to address than mentalistic notions of the self. Since the 1970 s mirrors have been used as the main tool to investigate self-recognition in the visual domain. Evidence for self-recognition is either in the form of spontaneous, self-directed, exploratory behaviours to the mirror image (Swartz, Sarauw \& Evans, 1999) or subjects targeting visual markings administered to a body part that is not visible without the aid of a mirror (the "mirrormark" test; Gallup, 1970).

Gallup's (1970) research on chimpanzees and macaques was pioneering, followed by studies on a range of other primate species, including humans (Amsterdam, 1972), chimpanzees (Lethmate \& Dücker, 1973; Suárez \& Gallup, 1981; Calhoun \& Thompson, 1988; Swartz \& Evans, 1991; Lin, Bard \& Anderson, 1992; Povinelli et al., 1993), bonobos (Hyatt \& Hopkins, 1994;

47 Westergaard \& Hyatt, 1994; Walraven, Van Elsacker \& Verheyen, 1995), gorillas (Suárez \& 48 Gallup, 1981; Ledbetter \& Basen, 1982; Posada \& Colell, 2007), orang-utans (Lethmate \&

49 Dücker, 1973; Suárez \& Gallup, 1981), gibbons and siamangs (Lethmate \& Dücker, 1973;

50 Inoue-Nakamura, 1997; Suddendorf \& Collier-Baker, 2009), monkeys (Lethmate \& Dücker,

51 1973; Inoue-Nakamura, 1997) and prosimians (Inoue-Nakamura, 1997) (see Anderson, 1984 for

52 review in primates). Within the non-human primates, great apes generally appear to be capable 
53 of mirror self-recognition (see Swartz, Sarauw \& Evans, 1999 for review), although there are

54 also multiple reports of failure (e.g., gorillas: Shillito et al., 1999). In bonobos, evidence for

55 mirror self-recognition is in terms of mirror-guided, self-directed behaviours, e.g., subjects

56 picking the teeth or eyes (Hyatt \& Hopkins, 1994; Westergaard \& Hyatt, 1994), in some

57 instances from first exposure (Walraven, Van Elsacker \& Verheyen, 1995). Monkeys (Macaca

58 silenus, Mandrillus sphinx, Papio hamadryas, Ateles sp., Cebus apella) generally fail the

59 'mirror-mark' test (Lethmate \& Dücker, 1973; Ujhelyi et al., 2000; Heschl \& Fuchsbichler,

60 2009; Suddendorf \& Collier-Baker, 2009) and we are not aware of any positive evidence for

61 spontaneous, self-directed behaviours in front of mirrors (Inoue-Nakamura, 1997). In one study,

62 Hauser et al. (1995) used a modified 'mirror-mark' test by colour-dying cotton-top tamarins'

63 (Saguinus oedipus) head hair and reported that individuals touched their heads more often and

64 looked in the mirror longer than controls. However, the study was criticized because results were

65 not based on blind video scoring (Anderson \& Gallup, 1997). In a follow-up study, Hauser

66 (2001) then failed to replicate the original findings but argued that subjects had witnesses other

67 group members with colour-dyed hair, suggesting that this may have lowered their interest.

Mirror experiments have also been conducted with non-primate species, with positive evidence

70 in bottlenose dolphins (Marten \& Psarakos, 1994; Reiss \& Marino, 2001), Asian elephants

71 (Plotnik, de Waal \& Reiss, 2006) and even manta rays, the biggest brained of all fish (Ari \&

72 D'Agostino, 2016). At the same time, small-brained species, such as great tits, (Kraft et al.,

73 2017) or cichlid fish (Hotta, Komiyama \& Kohda, 2018), typically fail mirror self-recognition

74 tasks, suggesting that mirror self-recognition may be a property of large brains, regardless of

75 phylogeny (but see Gallup \& Anderson, 2018). At the same time, there are a number of 
76 (disputed) claims of mirror-self recognition in Clark's nutcrackers (Clary \& Kelly, 2016),

77 Eurasian magpies (Prior, Schwarz \& Güntürkün, 2008; but see Anderson \& Gallup, 2015) and cleaner wrasse (Kohda et al., 2019); but see (Vonk, 2020) (de Waal, 2019) but not in giant pandas (Ma et al., 2015), suggesting that the complexity of a species' social life may also play a role (Gallup, 1998; Prior, Schwarz \& Güntürkün, 2008).

In humans and great apes, the capacity to recognise one's self in a mirror emerges gradually and with experience, usually starting with social behaviours directed at the mirror (e.g., threatening or vocalising; Gallup, 1970), followed by spatial exploration (e.g., reaching or looking behind the mirror), contingency exploration (movements of mirror-image relative to subject's body) and self-exploration (teeth, eyes or genital regions; Swartz, Sarauw \& Evans, 1999). In Western human cultures, self-directed behaviours usually appear from 15-18 months of age and become fully expressed by 24 months, while photo self-recognition occurs later (e.g., Courage et al 2004; Amsterdam, 1972; Lewis \& Brooks-Gunn, 1979; but see Keller et al., 2004, 2005; Kärtner et al., 2012 for non-western cultures). In chimpanzees, early reactions to mirrors are similar in kind but

91 do not emerge before 24 months (Lin, Bard \& Anderson, 1992). Also, there are large individual differences with either much delayed onset (around 60 months: Swartz, Sarauw \& Evans, 1999) or no onset at all (e.g., Swartz \& Evans, 1991; Povinelli et al., 1993; Walraven, Van Elsacker \&

94 Verheyen, 1995). Mirror self-recognition studies have caused much debate on how such data 95 should be interpreted. On one end of the spectrum is the interpretation that positive evidence is 96 an indicator of self-awareness (Inoue-Nakamura, 1997; Gallup, 1998; Swartz, Sarauw \& Evans, 97 1999; Plotnik, de Waal \& Reiss, 2006) or a self-concept (“...a sense of continuity, a sense of 98 personal agency and a sense of identity"; Gallup 1998, p. 240). At the other end, reactions 
99 towards administered marks have been interpreted as mere artefacts of experimental

100 manipulations and that mirror experiments reveal nothing about cognitive capacities (Heyes,

101 1994, 1995, 1996). More intermediate positions are that such behaviour qualifies as evidence for

102 self-perception, that is, recognising one's own visual appearance (Nielsen, Suddendorf \&

103 Slaughter, 2006) and perhaps even that one's own body is a separate entity from the surrounding

104 world (a 'body concept'). The 'body-concept' hypothesis has been investigated in developing

105 children, with the conclusion that such awareness emerges in the second year of life, correlated

106 with passing the 'mirror-mark' test (Moore et al., 2007). The notion of a 'body concept' is also

107 key to an alternative hypothesis to self-recognition: kinaesthetic-visual matching. Here, the idea

108 is that subjects act on the contingency between the kinaesthetic sensations (caused by their body

109 movements) and the corresponding movements of the image in the mirror (Mitchell, 1993,

110 1997). Crucially, however, mirror self-recognition does not predict perpetual kinaesthetic-visual

111 matching; subjects may simply look at the mirror and know that what they see is them (Mitchell

112 1993).

113

114 Another way of testing self-recognition is by presenting non-contingent images, usually delayed

115 videos or simply photographs. Infants as young as 5 months appear to discriminate between

116 video images of themselves and those of peers or objects (Legerstee, Anderson \& Schaffer,

117 1998) and from 18-24 months they start to show the tell-tale spontaneous behaviours, such as

118 exploration of visually inaccessible body parts, in the absence of contingency cues (Lewis \&

119 Brooks-Gunn, 1979). Between 24 and 48 months the emergence of self-recognition from non-

120 contingent images becomes fully established, suggesting that the task is more difficult than self-

121 recognition in a mirror (Povinelli, Landau \& Perilloux, 1996). In particular, 24-36 month-old 
122 children had more difficulties to infer the presence of a sticker on their heads from watching

123 delayed video image of themselves than 36-48 month-old children. In a more recent study, Hirata

124 et al. (2017) used a similar variant of the 'mark-test' to test five subadult chimpanzees with

125 extensive mirror experience ( 3 of 5 recognised themselves in mirrors). Here, subjects were tested

126 with live video feedback, short-delayed video feedback (i.e., 1-4 seconds) and long-delayed

127 video footage of themselves (one week). Among the control conditions, the authors used video

128 footage of humans but not of conspecifics. The finding was that the three subjects capable of

129 mirror self-recognition removed stickers placed on their heads more effectively and exhibited

130 more self-directed behaviours than the other two individuals, when shown live and short-delayed

131 video feedback but not when shown long-delayed video footage or other control conditions.

132 Although the study lacked adequate controls (Vonk, 2018), self-recognition from delayed, non-

133 contingent self-images may be the most stringent test that an individual (human or non-human)

134 possesses a visual mental representation of their own appearance, and this appears to require

135 prior experience with mirrors.

136

137 In this study, we investigated whether bonobos had a generalised understanding of their own

138 physical appearance and whether this was dependent on experience with mirrors. To address this,

139 we tested how subjects responded to different visual images of themselves and others, including

140 when contingency cues were absent, and how mirror exposure influenced their performance. We

141 hypothesised that mirror-naïve individuals did not have a full understanding of their own visual

142 appearance, but that prolonged mirror experience could provide subjects with the crucial

143 experience. To address this, we tested mirror-naïve subjects with different visual representations

144 of themselves and others, including non-contingent video footage of themselves. Two years later, 
145 following a 3-month period of ad libitum access to a mirror, we retested the same subjects again

146 with the two critical conditions, i.e., non-contingent representations of themselves and others.

147 We assessed subjects' interest in the different stimuli by comparing looking times, based on the

148 fact that both human and nonhuman primates spend more time looking at novel than familiar

149 faces and other stimuli (e.g., patterns: (Fantz, 1964; Gunderson \& Sackett, 1984; Gunderson \&

150 Swartz, 1985); objects: (Bachevalier, Brickson \& Hagger, 1993; Pascalis \& Bachevalier, 1998);

151 conspecific faces: (Pascalis \& Bachevalier, 1998; Gothard, Erickson \& Amaral, 2004; Gothard,

152 Brooks \& Peterson, 2009; but see Winters, Dubuc \& Higham, 2015 for criticism). We predicted

153 that stimuli perceived as unfamiliar should cause longer looking times than stimuli perceived as

154 familiar (Pascalis \& de Schonen, 1994). Mirror self-recognition experiments do not typically test

155 whether individuals discriminate between self and others although such a design allows for direct 156 comparisons of attention.

\section{Method}

\section{Study site \& subjects}

159 The study was carried out at La Vallée des Singes Primate Park in Romagne (France) with a 160 group of bonobos $(2014: \mathrm{N}=17 ; 2016: \mathrm{N}=20$; table 1$)$ housed in an indoor enclosure $\left(400 \mathrm{~m}^{2}\right)$

161 with access to two outdoor wooded islands $\left(11,500 \mathrm{~m}^{2}\right)$. Experiments were carried out from

162 January to July 2014 and from February to July 2016. Eight subjects (table 1) participated in all

163 trials, which involved a 'looking-time' bias task with sequential stimulus presentation, a

164 paradigm originally developed in the late 1950s for research with pre-verbal human infants (e.g.,

165 Fantz, 1963; Winters, Dubuc \& Higham, 2015). 
167 Prior to testing, individuals were exposed to the equipment during one week to minimise any

168 potential effects of novelty. Video stimuli were then presented by means of an APPLE iPad

169 (screen size approx. $15 \times 20 \mathrm{~cm}$ ) placed behind a transparent Acrylic panel (Fig. 1a) to which a

170 PANASONIC HC-V100 full HD camera was mounted to record the subjects' reactions face-on.

171 The mirror stimulus was presented by means of a one-way mirror $(25 \times 30 \mathrm{~cm})$, attached behind

172 the same panel (Fig. $1 \mathrm{~b}$ and $\mathrm{c}$ ).

\section{Part 1 - Before mirror exposure}

174 The first part of this within-subject experiment was carried out in 2014 with $\mathrm{N}=8$ subjects (4

175 males, 4 females, age range 9-34 years). To our knowledge, subjects had no prior experience

176 with mirrors, but we consider it likely that some individuals already had experience with

177 reflecting surfaces, such as window glass or bodies of water. However, reflections in mirrors are

178 of a different quality in terms sharpness, contrast or colour accuracy, compared to reflections by

179 other surfaces, suggesting that subjects' experiences with reflections of their own bodies were

180 limited.

181

182 The experiment comprised five experimental conditions presented to all subjects in the following

183 order: (1) contingent video footage of self (live feedback of self, visible on an iPad: C self); (2)

184 contingent mirror image of self (live depiction of self, visible in a one-way mirror: mirror); (3)

185 non-contingent video footage of self (previously recorded video footage of self, visible on an

186 iPad: NC self); (4) non-contingent video footage of known group member (previously recorded

187 video footage of other group member visible on an iPad: known); (5) non-contingent video

188 footage of unknown conspecific (previously recorded video footage of unfamiliar conspecific

189 visible on an iPad: unknown) (see Table S1 and Table S2). 
191 Footage for 'NC self' and 'known' were recorded during the 'mirror' and 'C self' conditions.

192 Footage for 'unknown' ( $\mathrm{N}=2$ males; $\mathrm{N}=1$ female) were recorded at the 'Lola ya Bonobo'

193 Sanctuary in the Democratic Republic of the Congo (see Movie S1 and Movie S2 for sample

194 footage). In both the 'known' and 'unknown' conditions, the footage showed generally inactive

195 individuals glancing at the camera from time to time. Footage for stimulus presentation was

196 selected at random, resulting in $\mathrm{N}=6$ same-sex pairs and $\mathrm{N}=2$ opposite-sex pairs for the 'known'

197 condition and $\mathrm{N}=4$ same-sex and $\mathrm{N}=4$ opposite-sex pairs for the 'unknown' condition. An

198 alternative design would have been to control for sex (i.e., to compare same-sex and different-

199 sex footage) or to simply use same-sex footage. As this would have created sample size issues

200 we opted for randomly assigning footage of 'known' and 'unknown' individuals to our eight 201 subjects.

202

203 Each subject was presented with each of the five conditions once and in the same sequential 204 order over an eight-month period (see Table S2). Stimuli were presented only very briefly, for a 205 total of 30s, starting with the first glance from the subject towards the stimulus. A trial was 206 terminated after 30 s or as soon as a subject left. We are aware of the fact that fixed order

207 stimulus presentation designs carry the disadvantage of potentially creating cross-condition 208 dependencies. A completely randomised design might have been preferable but not practical due 209 to the low number of subjects available for testing. In particular, we regarded it as essential that

210 all subjects entered part 2 of the experiment with the exact same stimulus history. We also

211 considered it unlikely that dependencies across conditions played a role because stimulus 
212 exposure was very short (30s) and intervals between subsequent presentations were long (median

$213=38.5$ days, range: 0-95 days).

214

215 Trials were carried out only when a subject was alone and inactive (i.e., resting or observing) in

216 one of the indoor cages and at a suitable orientation and distance from the corridor $(0.3-2.0 \mathrm{~m})$.

217 The subject was exposed to one of two portable devices, an iPad or a one-way mirror, each with

218 a camera mounted to record looking responses (Fig. 1). From the video clips, we extracted

219 looking-time during stimulus presentation. Looking time as a proxy for familiarity as a whole is

220 not uncontroversial (e.g. Winters, Dubuc \& Higham 2015). In face recognition tasks, however,

221 looking time appears to be reliable, at least for primates, who generally look longer to unfamiliar

222 than familiar faces of conspecifics (Pascalis \& de Schonen, 1994; Pascalis \& Bachevalier, 1998;

223 Gothard, Erickson \& Amaral, 2004; Gothard, Brooks \& Peterson, 2009; Fujita, 1987; Demaria \&

224 Thierry, 1988). Subjects' responses were filmed with a PANASONIC HC-V100 full HD camera, 225 as explained before, and looking-time coded post-hoc from the video recordings. Coding was

226 blind insofar as all videos were randomly labelled so that the rater (GS) was unable to infer the

227 experimental condition. Videos were analysed frame-by-frame with MPEG Streamclip 1.9.2.

228 Looking time was determined by measuring the duration between the first glance towards the

229 stimulus and the beginning of gaze aversion. If multiple gazes occurred over the 30s stimulus

230 presentation, we added them up. All clips were coded independently and blindly by a second

231 rater (EG), which did not reveal any reliability issues (Pearson's correlation coefficient, $r=0.93$,

$232 \mathrm{~N}=56$ ). Besides looking time, we were also interested in any type of mirror-guide self-directed

233 behaviours, especially of body parts that are visually not directly accessible, such as the face, the

234 teeth, the eyes or the back. 
236 Eight of 17 adult group members were tested and analysed in this study (see Table 1). Regarding

237 the remaining individuals $(\mathrm{N}=9)$, one adult male $(\mathrm{BO})$ participated in all experimental conditions

238 but had to be excluded due to poor video quality that prevented accurate coding. Two further

239 individuals (NK and LUE) also had to be excluded because they were too close to the camera,

240 which prevented reliable coding of looking time. One adult female (LY) had to be excluded

241 because she participated in two conditions only. Finally, we were unable to test the remaining

242 two adult females (DNL and UK) due to their lack of interest and participation. The dependent

243 infants and juveniles (LO, MO and KLS) were not tested.

\section{Part 2 - After mirror exposure}

245 Fifteen months after the first part of the experiment, the same subjects were provided with

246 prolonged access to a large mirror $(45 \times 115 \mathrm{~cm})$ to gain extended full experience with mirror

247 reflections of themselves. The mirror was placed in front of a resting platform in the indoor

248 enclosure allowing extensive ad libitum access to all individuals over a period of three months

249 (i.e., from Nov 2015 to Feb 2016; approx. 2,000 hours). At this time of year, the group was kept

250 inside due to cold weather conditions and the park was closed to the public. Although we did not

251 quantify the amount of time and manner by which subjects interacted with the mirror, all subjects

252 had countless opportunities to familiarise themselves with their own mirror reflections.

253 According to the keepers, subjects did not spend noticeable amounts of time in front of the

254 mirror during this time, nor did they notice individuals inspecting themselves in ostensive ways.

255 In hindsight, it would have been interesting to collect systematic data on how exactly subjects

256 behaved in front of the mirror, both quantitatively and qualitatively. 
258 We were mainly interested in the effect of mirror experience on subjects' perception of their own

259 and others' non-contingent images. To this end, we retested all individuals that had participated

260 in part $1(\mathrm{~N}=8)$ with the two critical conditions from part 1, i.e., non-contingent video footage of

261 themselves and of unknown conspecifics. Stimulus presentation began 10 - 20 days after removal

262 of the mirror. All aspects of presentation were identical to part 1, including the video footage.

263 The time lapse between the first and second stimulus presentation for a given subject and

264 condition was held constant for each subject and averaged at approximately 22 months (see

265 Table S2).

\section{Statistical analyses}

267 In a first analysis, prior to the 3-month mirror exposure, we modelled looking time as the response variable, experimental condition as the main predictor variable and subject ID as the random intercept in a linear mixed model (LMM). We added age as a control predictor to account for the possibility that younger individuals might show more interest than older individuals (Westergaard \& Hyatt, 1994; Walraven, Van Elsacker \& Verheyen, 1995). Looking time and age were square root transformed to achieve homogenous and approximately normally distributed residuals. We tested this full model against an informed null model (Forstmeier \& Schielzeth, 2011), which included only age as predictor and subject ID as random intercept. We tested the difference between the full and null model with a likelihood ratio test (LRT, Dobson, 2002). Note that this comparison is equivalent to testing of 'experimental condition' (models with vs. without experimental condition as variable). Post hoc diagnostics were implemented in order to test the stability of the model. This entailed running the full model eight times, each time removing data of one of the eight individuals and permitted us to verify whether one of the individuals was influential with respect to the interpretation of our model results. Results of this 
281 procedure indicated stable model results, that is, exclusion of any one individual did not change

282 the conclusions of our analysis.

283

284 In a second analysis, we tested how looking time was affected by the interaction between

285 stimulus type (self vs. unknown, i.e., self $\mathrm{Y} / \mathrm{N}$ ) and mirror exposure (non-exposed vs. exposed,

286 i.e., exposed Y/N), again with a Linear Mixed Model. Once again, we controlled for age, which

287 was included in the respective null model, and implemented post-hoc diagnostics to test the

288 stability of the model, which returned stable model results.

289

290 Statistical analyses were carried out with R v. 3.1.2 and lme4 v. 1.1-11 (R Core Team, 2014;

291 Bates et al., 2015). Data are available in the electronic supplementary material (Dataset S1).

292

293 Compliance with ethical standards

294 All applicable international, national and institutional guidelines for the care and use of animals

295 were followed. The study was authorised and given ethical approval by the "La Vallée des

296 Singes" scientific coordinator and zoological director. Trials were carried out opportunistically

297 when and where subjects felt so inclined. The study was in line with the ARRIVE guidelines and 298 recommendations from the EAZA and the AFdPZ code of ethics.

300 Results

301 The first part of the experiment consisted of exposing subjects to different motion images of

302 themselves, of other group members and of unfamiliar conspecifics (see Table S2). The results of

303 the model indicated that looking time was affected by experimental condition (LRT, $\chi^{2}=25.87$, 
304 d.f. $=4, \mathrm{P}<0.001$; Fig. 2; Table 2), with short looking times in the ' $C$ self' and 'mirror'

305 conditions ( $<5.0$ of $30 \mathrm{~s})$ and three-fold longer looking times in the 'NC self' and 'unknown'

306 conditions, whereas looking times to 'known' individuals were intermediate (Fig. 2: model

307 estimates, Table 3: descriptive data). In other words, subjects showed most interest in images of

308 strangers and non-contingent images of themselves and least interest in contingent images of

309 themselves (video clips and mirror reflections), suggesting that non-contingent self-images were

310 perceived in the same way as unknown individuals. When coding the videos for gaze duration,

311 we did not notice any cases of self-inspecting behaviour in the two contingent conditions.

312

313 We then provided subjects with three months of ad libitum mirror access. Following this

314 manipulation, and almost two years after the previous trials, subjects were retested with non-

315 contingent footage of themselves (NC self) and strangers (unknown), the two conditions that

316 elicited most interest before (Fig. 2). When comparing interest before and after mirror exposure,

317 the full model was significantly different from the null model (LRT, $\chi^{2}=18.06$, d.f. $=3, \mathrm{P}<0.001$;

318 Fig. 3, Table 4), indicating that looking time differed as a function of mirror-exposure, stimulus

319 identity, and their interaction. The interaction effect was close to significance (LRT, $\chi^{2}=3.61$,

$320 \mathrm{df}=1, \mathrm{P}=0.057)$, as looking time substantially decreased after mirror exposure in the ' $N C$ self'

321 condition, but not in the 'unknown' condition (see fig 3 for model prediction means and SDs).

322 Targeted follow-up tests would be necessary to confirm the preliminary conclusion that

323 prolonged mirror exposure decreases subjects' interest in non-contingent self-images, while

324 interest in stranger individuals remained unchanged.

325

326 Discussion 
327 In this study, we were interested in how prolonged mirror-exposure influenced the response to

328 visual representations of the self. The underlying rationale was that, during human development,

329 recognition of non-contingent footage of the self is cognitively most challenging, suggesting that

330 bonobos may struggle with such stimuli, more than with contingent depictions of themselves. To

331 address this, we carried out a two-part experiment during which subjects watched motion images

332 depicting either themselves or another individual. Due to a number of constraints, discussed

333 below, we regard the conclusions of this study as preliminary.

335 In the first part, subject responses to three types of self-images (mirror reflection, contingent

336 video footage and non-contingent video footage) were compared with responses to video footage

337 of familiar and unfamiliar conspecifics. Results revealed low interest in the mirror and in

338 contingent self-footage, but high interest in the non-contingent self-footage condition, similar to

339 interest in unfamiliar individuals.

341 A first parsimonious explanation of this result might be that bonobos did not recognise

342 themselves in any of the three conditions (mirror, contingent, non-contingent), but that non343 contingent movement was simply more interesting than contingent movement. However, this

344 interpretation is at odds with the fact that the 'known' condition caused less interest than 'non-

345 contingent self' and 'unknown' conditions, all of which moved in asynchronous ways, so we

346 consider this explanation as unlikely.

348 A second explanation for the high interest in the 'non-contingent self' condition might be that

349 subjects did not recognise themselves and responded as if it were an unfamiliar individuals (fig 
350 2) whereas they did recognise themselves in the contingent footage and mirror images. This may

351 be because contingent self-recognition is easier to achieve than non-contingent self-recognition,

352 to the effect that experience with low-quality reflections (such as in windows or water surfaces)

353 could suffice to establish some level of self-recognition.

354

355 However, if subjects recognised themselves in the contingent conditions, then why did they not

356 show the usual tell-tale behaviours of self-recognition, such as exploration of their own teeth,

357 nose and other visually inaccessible body parts? Possible explanations for this absence is that

358 subjects were distracted by the experimenter or by the equipment, or that stimulus exposure was

359 simply too short (30s) to engage in self-exploration. However, it must also be stated that during

360 the subsequent prolonged mirror exposure, neither the keepers nor the researchers noted any self-

361 exploration by subjects, although we did not record the subjects' behaviour in the absence of

362 observers.

363

364 The fact that subjects showed little interest in the contingent stimuli suggests that they were

365 already (somewhat) familiar with their own reflections, possibly from windows, water surfaces

366 or their own shadows, but that this was not be enough to develop a full sense of how one looks.

367 Self-recognition, in other words, may not be an all-or-nothing state in bonobos, but a gradually

368 acquired cognitive achievement.

370 In the second part of the experiment, we provided subjects with extended experience of self-

371 reflections by giving them uninterrupted access to a mirror for three consecutive months. We

372 predicted that this experience should enable subjects to familiarise themselves with a wider range 
373 of visual depictions of themselves, which would allow them to generalise and form a mental

374 representation of their own visual appearance. We only retested subjects with the two critical

375 stimuli (non-contingent footage of self and unknown individuals), 10-20 days after the mirror

376 was removed, and found interest in the non-contingent footage significantly decreased, while

377 interest in strangers remained similar (fig. 3). In hindsight, a further interesting comparison

378 would have been to also rerun the 'known' condition as a control. Based on the fact that the

379 subjects had extensive opportunities to observe each other daily, we would not have predicted

380 any change in interest in this condition after the mirror-exposure.

381

382 Could results be explained by low-level stimulus habituation to differences in background? We

383 find this an unlikely scenario since stimulus presentations were exceedingly short (30s) and

384 presented twice only over a period of 22 months, rendering perceptual habituation an implausible

385 scenario. Related to this, subjects could have paid more attention to some backgrounds than

386 others. Although we cannot rule this out completely, the looking time data are at odds with such

387 an explanation: Despite similar backgrounds, responses to non-contingent self and known

388 individuals were different, while responses to non-contingent self and strangers were similar,

389 despite different backgrounds.

390

391 As it stands, our results are thus consistent with two hypotheses, i.e., that subjects responded to

392 differences in perceived familiarity or that they recognized some faces as their own. At the very

393 least, therefore, subjects must have managed to familiarise themselves with all aspects of their

394 visual appearance, allowing them to categorise the 'non-contingent self' footage as more familiar

395 compared to the stranger footage. But whether subjects really proceeded to form a true mental 
396 concept of their own visual appearance ("that's me"), as opposed to some lower level sense of

397 familiarity, will have to be addressed by future research. For instance, subjects could be shown

398 (ideally contingent) footage of the stranger individuals to control for the extra time they were

399 granted to watch themselves in the mirror. For example, subjects could be shown footage of the

400 stranger individuals interacting with the mirror images, but such that the filmed mirror reflection

401 only revealed their faces. If despite this extra experience they continued to show higher interest

402 in the non-contingent footage of strangers, familiarity is the less likely explanation, suggesting

403 that subjects understood that the individual in the video clip was them (J Vonk, personal

404 communication).

405

406 Conclusion

407 Our data suggest that, given sufficient mirror exposure, bonobos acquire the ability to use mirror-

408 reflections of themselves to learn about their own physical appearance in more generalised way.

409 In contrast to other research, our results suggest that this level of awareness can be detached

410 from the here and now and can include visual non-contingent representations of the self.

411 Whether this was achieved by responding to differences in perceived familiarity or full self-

412 recognition cannot be conclusively decided by our investigation. Much remains to be elucidated

413 regarding the mechanisms and the implications of great apes' capacity of self-recognition, such

414 as the amount of mirror exposure minimally necessary or the stability of the resulting self-

415 recognition over time (see Calhoun \& Thompson (1988) de Veer et al. (2003).

\section{Acknowledgements}

417 We thank "La Vallée des Singes" and its director, Emmanuel Le Grelle, as well as "Le

418 Conservatoire pour la Conservation des Primates" for allowing access to the study site and 
419 subjects. We also thank the keepers, Carole Michelet, Franck Alexieff, Lise Morel, Jérémy

420 Mergault and Alexandre Albert for their valuable help in carrying out the experiment. Many

421 thanks to Christof Neumann for his statistical advice and for valuable discussions and support.

422 We thank Jennifer Vonk and the reviewers for their very enlightening critic and ideas for future 423 research.

\section{References}

425 Amsterdam B. 1972. Mirror self-image reactions before age two. Developmental Psychobiology $426 \quad 5: 297-305$.

427 Anderson JR. 1984. Monkeys with mirrors: Some questions for primate psychology.

428 International Journal of Primatology 5:81-98.

429 Anderson JR, Gallup GG. 2015. Mirror self-recognition: a review and critique of attempts to 430 promote and engineer self-recognition in primates. Primates 56:317-326. DOI: 10.1007/s10329-015-0488-9.

Anderson, J. and J. G. Gallup (1997). "Self-recognition in Saguinus? A critical essay." Anim Behav 54:

433 $1559-1563$.

Ari C, D’Agostino DP. 2016. Contingency checking and self-directed behaviors in giant manta 435 rays: Do elasmobranchs have self-awareness? Journal of Ethology 34:167-174. DOI: 10.1007/s10164-016-0462-z.

Bachevalier J, Brickson M, Hagger C. 1993. Limbic-dependent recognition memory in monkeys develops early in infancy. NeuroReport 4:77-80.

Bates D, Mächler M, Bolker B, Walker S. 2015. Fitting linear mixed-effects models using lme4. Journal of Statistical Software 67:1-48. DOI: 10.18637/jss.v067.i01. 
441 Calhoun S, Thompson RL. 1988. Long-term retention of self-recognition by chimpanzees.

$442 \quad$ American Journal of Primatology 15:361-365.

443 Clary D, Kelly DM. 2016. Graded mirror self-recognition by Clark's nutcrackers. Scientific $444 \quad$ Reports 6:36459. DOI: 10.1038/srep36459.

445 Courage, M. L., S. C. Edison and M. L. Howe (2004). "Variability in the early development of visual 446 self-recognition." Infant Behavior \& Development 27(4): 509-532.

447 Dale R, Plotnik JM. 2017. Elephants know when their bodies are obstacles to success in a novel transfer task. Scientific Reports 7:46309. DOI: 10.1038/srep46309.

449 Demaria C, Thierry B. 1988. Responses to animal stimulus photographs in stumptailed macaques 450 (Macaca arctoides). Primates 29:237-244.

451 de Waal, F. B. M. 2019. Fish, mirrors, and a gradualist perspective on self-awareness. Plos 452 Biology, 17(2), 8, Article e3000112.

453 Dobson AJ. 2002. An introduction to generalized linear models. Boca Raton, USA: Chapman \& 454 Hall/CRC.

455

456

457

458

460

461

462

463

Dufour V, Pascalis O, Petit O. 2006. Face processing limitation to own species in primates: A comparative study in brown capuchins, Tonkean macaques and humans. Behavioural Processes 73:107-113. DOI: 10.1016/j.beproc.2006.04.006.

Fantz RL. 1963. Pattern vision in newborn infants. Science 140:296-297.

Fantz RL. 1964. Visual experiences in infants: Decreased attention to familiar patterns relative to novel ones. Science 146:668-670.

Forstmeier W, Schielzeth H. 2011. Cryptic multiple hypotheses testing in linear models: overestimated effect sizes and the winner's curse. Behavioral Ecology and Sociobiology 65:47-55. DOI: 10.1007/s00265-010-1038-5. 
464 Fujita K. 1987. Species recognition by five macaque monkeys. Primates 28:353-366.

465 Gallup GG. 1970. Chimpanzees: Self-recognition. Science 167:86-87.

466 Gallup GG. 1982. Self-awareness and the emergence of mind in primates. American Journal of 467 Primatology 2:237-248.

468 Gallup GG. 1991. Toward a comparative psychology of self-awareness: Species limitations and 469 cognitive consequences. In: Strauss J, Goethals GR eds. The Self: Interdisciplinary Approaches. New York, NY: Springer, 121-135.

471 Gallup GG. 1998. Self-awareness and the evolution of social intelligence. Behavioural Processes

472 42:239-247.

Gallup GG, Anderson JR. 2018. The "olfactory mirror" and other recent attempts to demonstrate

474

475

476

477

478

479

480

481

482

483

484

485

486 self-recognition in non-primate species. Behavioural Processes 148:16-19. DOI: 10.1016/j.beproc.2017.12.010.

Gergely G. 1994. From self-recognition to theory of mind. In: Parker ST, Mitchell RW, Boccia ML eds. Self-awareness in animals and humans: Developmental perspectives. Cambridge, UK: Cambridge University Press, 51-60.

Gothard KM, Brooks KN, Peterson MA. 2009. Multiple perceptual strategies used by macaque monkeys for face recognition. Animal Cognition 12:155-167. DOI: 10.1007/s10071-0080179-7.

Gothard KM, Erickson CA, Amaral DG. 2004. How do rhesus monkeys (Macaca mulatta) scan faces in a visual paired comparison task? Animal Cognition 7:25-36. DOI: 10.1007/s10071-003-0179-6.

Gunderson VM, Sackett GP. 1984. Development of pattern recognition in infant pigtailed macaques (Macaca nemestrina). Developmental Psychology 20:418-426. 
487 Gunderson VM, Swartz KB. 1985. Visual recognition in infant pigtailed macaques after a 24488 hour delay. American Journal of Primatology 8:259-264.

489 Hauser, M. D., J. Kralik, C. Bottomahan, M. Garrett and J. Oser (1995). "Self-Recognition in Primates $490 \quad$ Phylogeny and the Salience of Species-Typical Features." Proceedings of the National Academy 491 of Sciences of the United States of America 92(23): 10811-10814.

492 Hauser, M. D. (2001). "Cotton-top tamarins fail to show mirror-guided self-exploration." Am J Primatol 493 53: $131-137$.

494 Heschl A, Fuchsbichler C. 2009. Siamangs (Hylobates syndactylus) recognize their mirror 495 image. International Journal of Comparative Psychology 22:221-233.

496

497

498

499 500

501 502 Behaviour 50:1533-1542.

Heyes CM. 1996. Self-recognition in primates: irreverence, irrelevance and irony. Animal Behaviour 51:470-473.

Hirata S, Fuwa K, Myowa M. 2017. Chimpanzees recognize their own delayed self-image. Royal Society Open Science 4:1-9. DOI: 10.1098/rsos.170370.

Hotta T, Komiyama S, Kohda M. 2018. A social cichlid fish failed to pass the mark test. Animal Cognition 21:127-136. DOI: 10.1007/s10071-017-1146-y.

Hyatt CW, Hopkins WD. 1994. Self-awareness in bonobos and chimpanzees: A comparative perspective. In: Parker ST, Mitchell RW, Boccia ML eds. Self-awareness in animals and humans: Developmental perspectives. New York: Cambridge University Press, 248-253.

Inoue-Nakamura N. 1997. Mirror Self-recognition in Nonhuman Primates: A Phylogenetic Approach. Japanese Psychological Research 39:266-275. 
510 Kärtner J, Keller H, Chaudhary N, Yovsi R. 2012. The development of mirror self-recognition in

511 different sociocultural contexts. Monographs of the Society for Research in Child

$512 \quad$ Development 77.

513 Keller H, Kärtner J, Borke J, Yovsi R, Kleis A. 2005. Parenting styles and the development of 514 the categorical self: A longitudinal study on mirror self-recognition in Cameroonian Nso 515 and German families. International Journal of Behavioral Development 29:496-504.

516 DOI: $10.1080 / 01650250500147485$.

517 Keller H, Yovsi R, Borke J, Kartner J, Jensen H, Papaligoura Z. 2004. Developmental

518 consequences of early parenting experiences: Self-recognition and self-regulation in three

519 cultural communities. Child Development 75:1745-1760. DOI: 10.1111/j.1467-

$520 \quad$ 8624.2004.00814.x.

521 Kohda, M., Hotta, T., Takeyama, T., Awata, S., Tanaka, H., Asai, J. Y., \& Jordan, A. L. 2019. If

522 a fish can pass the mark test, what are the implications for consciousness and self-

$523 \quad$ awareness testing in animals? Plos Biology, 17(2), Article e3000021.

524 Kraft F-L, Forštová T, Utku Urhan A, Exnerová A, Brodin A. 2017. No evidence for self-

525 recognition in a small passerine, the great tit (Parus major) judged from the mark/mirror 526 test. Animal Cognition 20:1049-1057. DOI: 10.1007/s10071-017-1121-7.

527 Ledbetter DH, Basen JA. 1982. Failure to demonstrate self-recognition in gorillas. American $528 \quad$ Journal of Primatology 2:307-310.

529 Legerstee M, Anderson D, Schaffer A. 1998. Five- and eight-month-old infants recognize their 530 faces and voices as familiar and social stimuli. Child Development 69:37. DOI: $10.2307 / 1132068$. 
532 Lethmate J, Dücker G. 1973. Untersuchungen zum selbsterkennen im spiegel bei orang-utans 533 und einigen anderen affenarten. Ethology 33:248-269.

534 Lewis M, Brooks-Gunn J. 1979. Social cognition and the acquisition of self. Boston: Springer $535 \quad$ US.

536 Lin AC, Bard KA, Anderson JR. 1992. Development of self-recognition in chimpanzees (Pan 537 troglodytes). Journal of Comparative Psychology 106:120-127.

538

539

540

541

542

543

544

545

546

547

548

549

550

551

552

553

554

Ma X, Jin Y, Luo B, Zhang G, Wei R, Liu D. 2015. Giant pandas failed to show mirror selfrecognition. Animal Cognition 18:713-721. DOI: 10.1007/s10071-015-0838-4.

Marten K, Psarakos S. 1994. Evidence of self-awareness in the bottlenose dolphin (Tursiops truncatus). In: Parker ST, Mitchell RW, Boccia ML eds. Self-awareness in animals and humans: Developmental perspectives. New York: Cambridge University Press, 361-379.

Mitchell RW. 1993. Mental models of mirror-self-recognition: Two theories. New Ideas in Psychology 11:295-325. DOI: 10.1016/0732-118X(93)90002-U.

Mitchell RW. 1997. Kinesthetic-visual matching and the self-concept as explanations of mirrorself-recognition. Journal for the Theory of Social Behaviour 27:17-39.

Mitchell RW. 2012. Self recognition in animals. In: Leary MR, Tangney JP eds. Handbook of self and identity. New York: The Guilford Press, 656-679.

Moore C, Moore C, Mealiea J, Garon N, Povinelli DJ. 2007. The development of body selfawareness. Infancy 11:157-174.

Nielsen M, Suddendorf T, Slaughter V. 2006. Mirror self-recognition beyond the face. Child Development 77:176-185.

Pascalis O, Bachevalier J. 1998. Face recognition in primates: a cross-species study. Behavioural Processes 43:87-96. 
555 Pascalis O, de Schonen S. 1994. Recognition memory in 3- to 4-day-old human neonates:

556 NeuroReport 5:1721-1724. DOI: 10.1097/00001756-199409080-00008.

557 Plotnik JM, de Waal FransBM, Reiss D. 2006. Self-recognition in an Asian elephant.

$558 \quad$ Proceedings of the National Academy of Sciences 103:17053-17057.

559 Posada S, Colell M. 2007. Another gorilla (Gorilla gorilla gorilla) recognizes himself in a mirror. $560 \quad$ American Journal of Primatology 69:576-583. DOI: 10.1002/ajp.20355.

561 Povinelli DJ, Landau KR, Perilloux HK. 1996. Self-recognition in young children using delayed versus live feedback: Evidence of a developmental asynchrony. Child Development 67:1540-1554. DOI: 10.2307/1131717.

564 Povinelli DJ, Rulf AB, Landau KR, Bierschwale DT. 1993. Self-recognition in chimpanzees (Pan troglodytes): distribution, ontogeny, and patterns of emergence. Journal of Comparative Psychology 107:347-372.

567 Prior H, Schwarz A, Güntürkün O. 2008. Mirror-induced behavior in the magpie (Pica pica): 568 evidence of self-recognition. PLoS Biology 6:e202.

569 R Core Team. 2014. R: A language and environment for statistical computing. Vienna, Austria:

$570 \quad$ R Foundation for Statistical Computing.

571 Reiss D, Marino L. 2001. Mirror self-recognition in the bottlenose dolphin: A case of cognitive 572 convergence. Proceedings of the National Academy of Sciences 98:5937-5942.

573 Roder BJ, Bushnell EW, Sasseville AM. 2000. Infants' preferences for familiarity and novelty 574 during the course of visual processing. Infancy 1:491-507.

575 Shillito, D., J. G. Gallup and B. Beck (1999). "Factors affecting mirror behavior in west- ern 576 lowland gorillas, Gorilla gorilla." Anim Behav 57: 999-1004. 
577 Shinskey JL, Munakata Y. 2005. Familiarity breeds searching: Infants reverse their novelty

578 preferences when reaching for hidden objects. Psychological Science 16:596-600.

579 Suárez SD, Gallup GG. 1981. Self-recognition in chimpanzees and orangutans, but not gorillas.

$580 \quad$ Journal of Human Evolution 10:175-188.

581 Suddendorf T, Collier-Baker E. 2009. The evolution of primate visual self-recognition: evidence

582 of absence in lesser apes. Proceedings of the Royal Society B: Biological Sciences

583 276:1671-1677. DOI: 10.1098/rspb.2008.1754.

584 Swartz KB, Evans S. 1991. Not all chimpanzees (Pan troglodytes) show self-recognition.

$585 \quad$ Primates 32:483-496.

586 Swartz KB, Sarauw D, Evans S. 1999. Comparative aspects of mirror self-recognition in great apes. In: Parker ST, Mitchell RW, Miles HL eds. The mentalities of gorillas and orangutans: Comparative perspectives. Cambridge, UK: Cambridge University Press, 283-294.

Ujhelyi M, Merker B, Buk P, Geissmann T. 2000. Observations on the behavior of gibbons (Hylobates leucogenys, H. gabriellae, and H. lar) in the presence of mirrors. Journal of Comparative Psychology 114:253-262. DOI: 10.1037//0735-7036.114.3.253.

de Veer MW, Gallup GG, Theall LA, van den Bos R, Povinelli DJ. 2003. An 8-year longitudinal study of mirror self-recognition in chimpanzees (Pan troglodytes). Neuropsychologia 41:229-234.

Vonk, J. 2018. Are chimpanzees "stuck" on their "selves" in video? Learning \& Behavior, 46(3), 227-228.

598 Vonk, J. 2020. A fish eye view of the mirror test. Learning \& Behavior, 48(2), 193-194. 
599 Walraven V, Van Elsacker L, Verheyen R. 1995. Reactions of a group of pygmy chimpanzees

600 (Pan paniscus) to their mirror-images: evidence of self-recognition. Primates 36:145$601 \quad 150$.

602 Westergaard GC, Hyatt CW. 1994. The responses of bonobos (Pan paniscus) to their mirror 603 images: evidence of self-recognition. Human Evolution 9:273-279.

604 Winters S, Dubuc C, Higham JP. 2015. Perspectives: The looking time experimental paradigm in 605 studies of animal visual perception and cognition. Ethology 121:625-640. DOI:

$606 \quad 10.1111 /$ eth. 12378.

607 


\section{Figure 1}

Portable acrylic panel for stimulus presentation.

(A) Video camera and iPad displaying a non-contingent video stimulus. (B) Video camera and one-way mirror (front). (C) Video camera and one-way mirror (back). Photos by G.Shorland.

*Note: Auto Gamma Correction was used for the image. This only affects the reviewing manuscript. See original source image if needed for review.
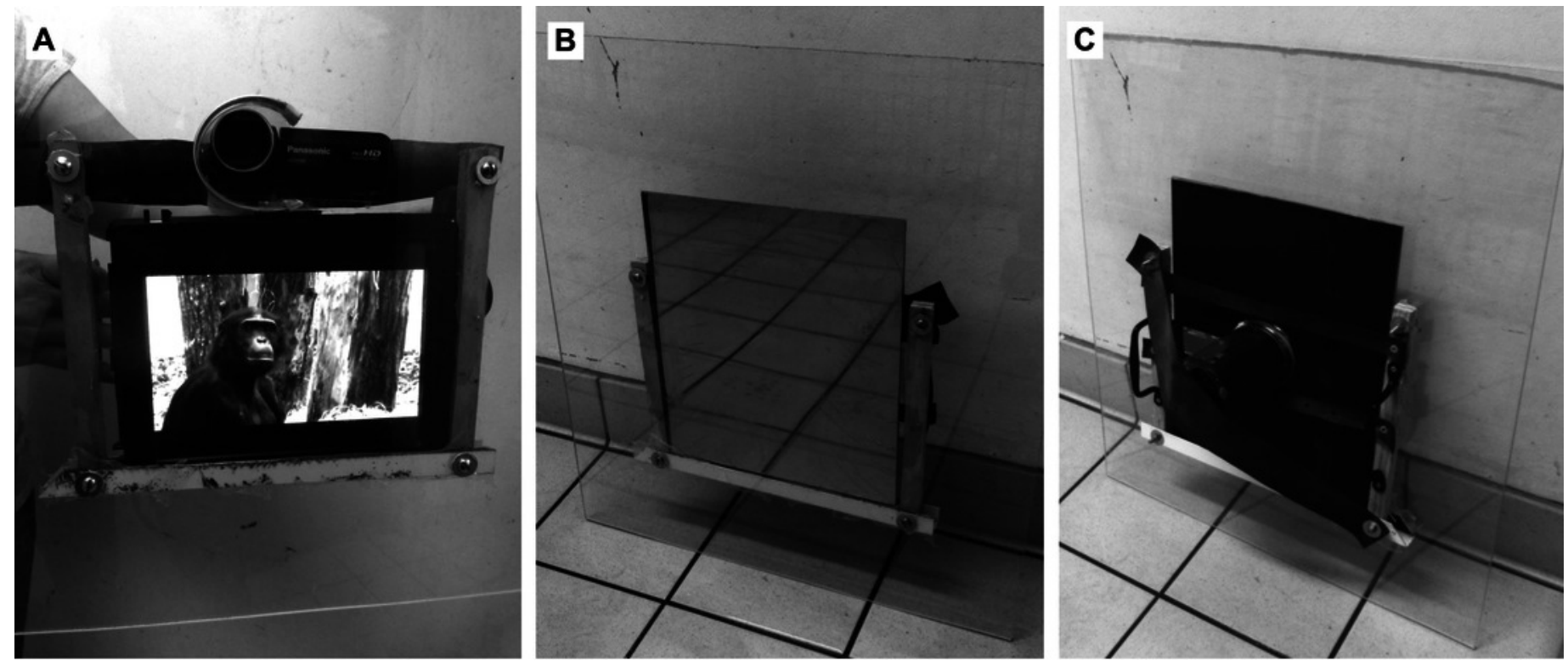
Figure 2

Subject looking time and model predictions for the five test conditions.

Subject looking time (circles) and model prediction (squares) for the five test conditions with 95\% confidence interval; note that looking time was square root transformed for modeling but for presentation we back-transformed it along the y axis. Conditions are presented chronologically from left to right.

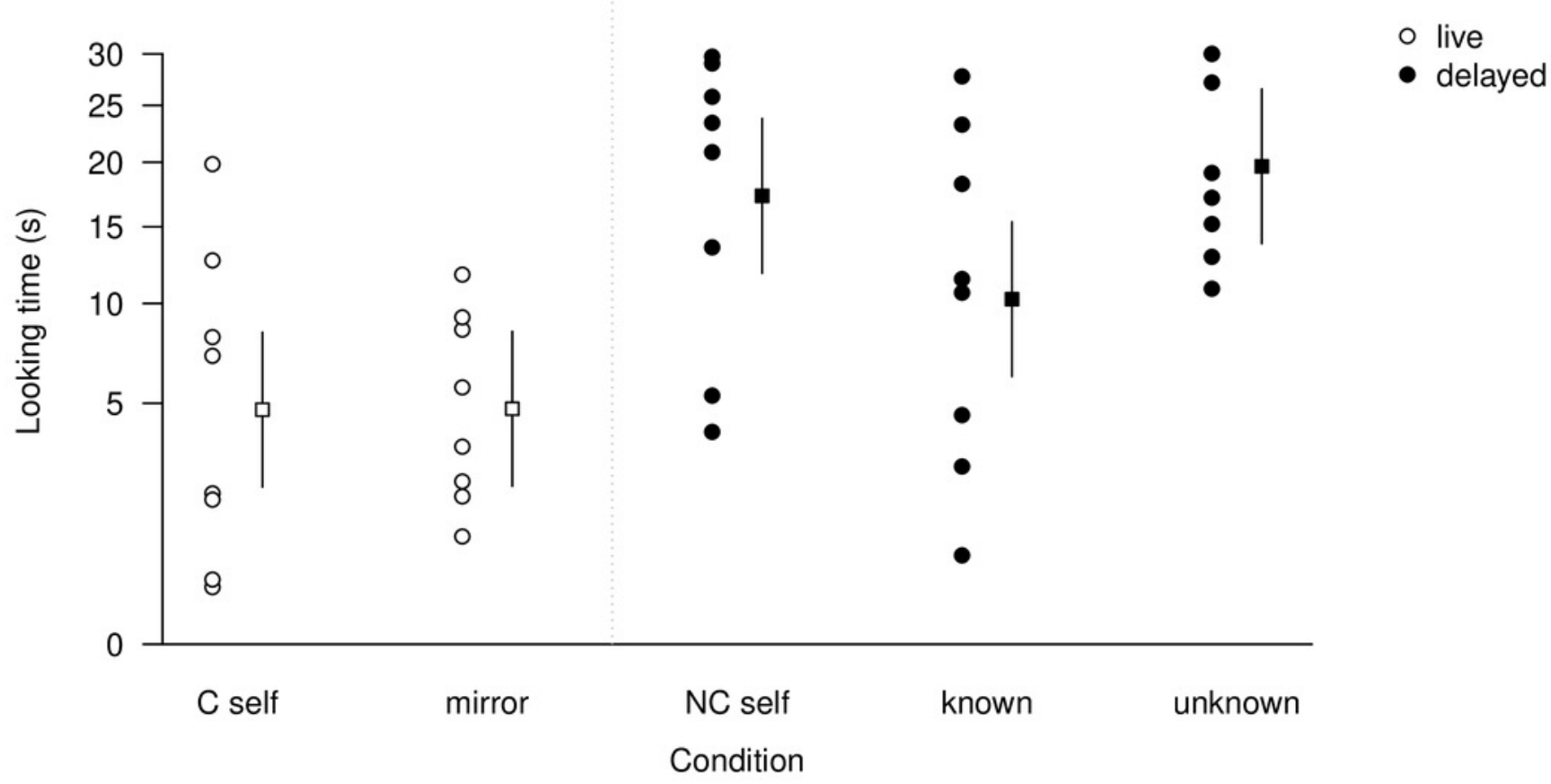


Figure 3

Subject looking time and model predictions before and after mirror exposure.

Subject looking time and model prediction before and after mirror exposure. Looking time (circles) before and after three-months ad libitum mirror exposure. Model predictions (squares) are given with 95\% confidence intervals; note that looking time was square root transformed for modelling but for presentation we back-transformed it along the y axis.

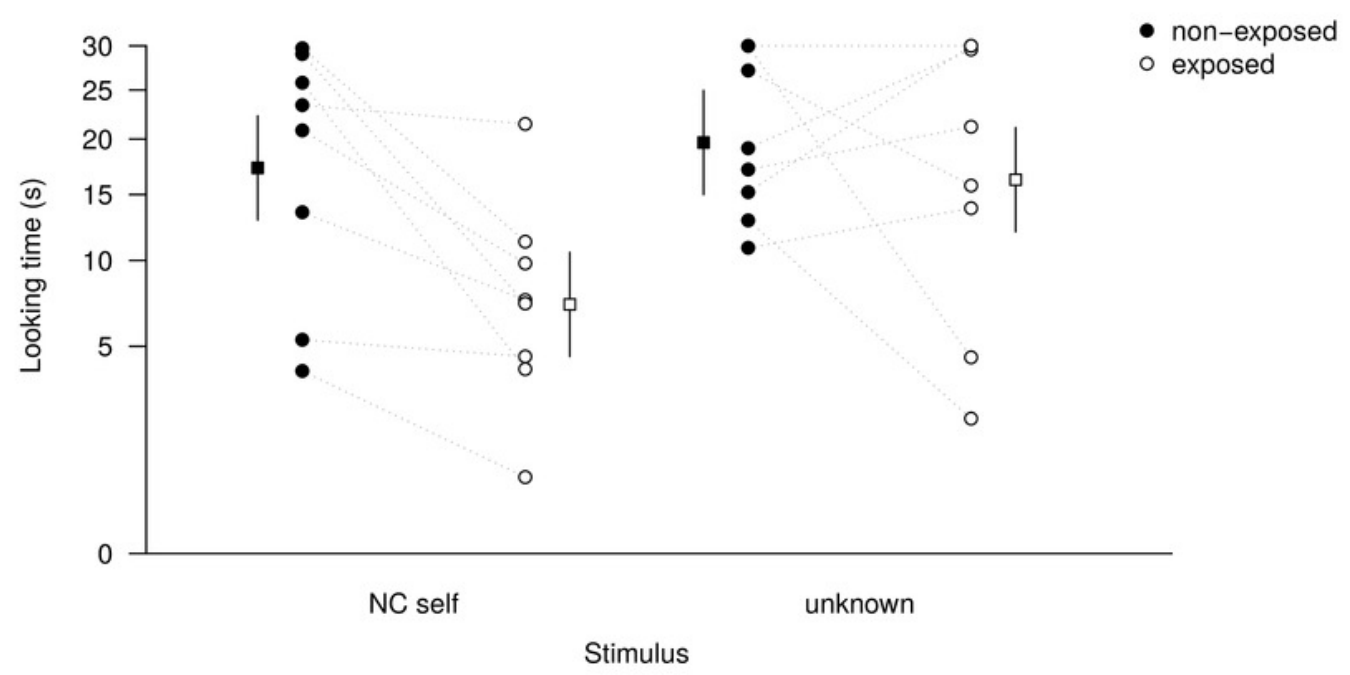




\section{Table $\mathbf{1}$ (on next page)}

Study subjects housed at La Vallée des Singes primate park, France.

Individuals having participated in all trials are indicated in bold $(\mathrm{N}=8)$. Individuals marked by an asterisk initially participated but were excluded for reasons detailed below. Age-class as defined by Kano (1984) at beginning of study. 
1 Table 1. Study subjects housed at La Vallée des Singes primate park, France

\begin{tabular}{|c|c|c|c|c|c|}
\hline \multicolumn{2}{|l|}{ Individual } & Code & Sex & Age-Class & Year of birth \\
\hline Daniela & & DNL & F & Adult & 1968 \\
\hline Lisala & & LSL & $\mathbf{F}$ & Adult & 1980 \\
\hline Ukela & & UK & $\mathrm{F}$ & Adult & 1985 \\
\hline Bondo & $*$ & $\mathrm{BO}$ & M & Adult & 1991 \\
\hline Kirembo & & $\mathbf{K I}$ & $\mathbf{M}$ & Adult & 1992 \\
\hline Ulindi & & $\mathbf{U L}$ & $\mathbf{F}$ & Adult & 1993 \\
\hline Diwani & & DW & $\mathbf{M}$ & Adult & 1996 \\
\hline David & & DV & $\mathbf{M}$ & Adult & 2001 \\
\hline Khaya & & KH & F & Adult & 2001 \\
\hline Lingala & & LNG & $\mathbf{F}$ & Sub-adult & 2003 \\
\hline Lucy & $*$ & LY & $\mathrm{F}$ & Sub-adult & 2003 \\
\hline Kelele & & KEL & $\mathbf{M}$ & Sub-adult & 2004 \\
\hline Luebo & $*$ & LUE & M & Sub-adult & 2006 \\
\hline Nakala & $*$ & NK & F & Juvenile & 2007 \\
\hline Loto & & LO & M & Juvenile & 2009 \\
\hline Moko & & MO & M & Infant & 2012 \\
\hline Khalessi & & KLS & $\mathrm{F}$ & Infant & 2012 \\
\hline
\end{tabular}

2 Individuals having participated in all trials are indicated in bold $(\mathrm{N}=8)$. Individuals

3 marked by an asterisk initially participated but were excluded for reasons detailed

4 below. Age-class as defined by Kano (1984) at beginning of study. 
Table 2 (on next page)

Result of the LMM testing the effect of condition on looking time. 
1 Table 2. Result of the LMM testing the effect of condition on looking time

\begin{tabular}{llll}
\hline & Estimate & Standard error & $t$ \\
\hline Intercept & 3.18 & 0.44 & 7.18 \\
Condition (C self) & & & \\
- Mirror & 0.01 & 0.49 & 0.02 \\
- NC Self & 1.98 & 0.49 & 4.03 \\
- Known & 1.03 & 0.49 & 2.08 \\
- Unknown & 2.26 & 0.49 & 4.58 \\
Age & -0.12 & 0.03 & -3.75 \\
\hline
\end{tabular}

2 


\section{Table 3(on next page)}

Descriptive results: experimental condition, mirror exposure, median looking-time and quartiles calculated from raw data. 
1 Table 3. Descriptive results: experimental condition, mirror exposure, median looking-time and quartiles 2 calculated from raw data.

\begin{tabular}{llll}
\hline Condition & Mirror exposure & Median looking time & Quartiles \\
\hline C self & non-exposed & 4.6 & $1.4-9.3$ \\
mirror & non-exposed & 4.5 & $2.2-8.7$ \\
NC self & non-exposed & 22.1 & $11.5-26.6$ \\
known & non-exposed & 11.1 & $4.1-19.5$ \\
unknown & non-exposed & 18.1 & $14.6-27.9$ \\
\hline NC self & exposed & 7.4 & $4.4-10.2$ \\
Unknown & exposed & 18.5 & $11.5-29.7$ \\
\hline
\end{tabular}

3 


\section{Table 4 (on next page)}

Result of the LMM, testing the effects of stimulus identity (self vs. unknown) and mirrorexposure (non-exposed vs. exposed) on looking time. 
1 Table 4. Result of the LMM, testing the effects of stimulus identity (self vs. unknown) and mirror2 exposure (non-exposed vs. exposed) on looking time.

\begin{tabular}{llll}
\hline & Estimate & Standard error & $t$ \\
\hline Intercept & 5.85 & 0.35 & 16.63 \\
Mirror-exposure (non-exposed) & & & \\
- exposed & -0.40 & 0.39 & -1.04 \\
Stimulus identity (non-self) & & & \\
- self & -0.27 & 0.39 & -0.71 \\
Mirror exposure : Stimulus identity & -1.07 & 0.55 & -1.96 \\
Age & -0.17 & 0.03 & -6.41 \\
\hline
\end{tabular}

3 